\title{
First-principles Calculations of Structures and Micro-cracks of the Al-Ni Crystal Materials
}

\author{
Zhong-Hao ZHOU ${ }^{1, a}$, Zhen ZHAO ${ }^{2, b}$, Hong-Bin WANG ${ }^{1, c, *}$ and Zhi $\mathrm{LI}^{1, \mathrm{~d}}$ \\ ${ }^{1}$ School of Materials and Metallurgy, University of Science and Technology Liaoning, Anshan \\ 114051, PR China \\ 2 School of Chemistry and Life Science, Anshan Normal University, Anshan 114007, PR China \\ aemail:zzh1193@126.com, bemail:zhaozhenlunwen@yeah.net, 'email:whb6055@163.com, \\ demail:lizhi81723700@163.com.
}

*Corresponding author:whb6055@163.com

Keywords: Structures, Elastic anisotropy, Toughness, Debye temperature, Density Functional Theory

\begin{abstract}
The structures, elastic anisotropy, toughness, and Debye temperature of the Al-Ni crystal are analyzed by using the density functional theory: PW91. The results show that AlNi is the most anisotropic of all phase, and the $\mathrm{Al}_{3} \mathrm{Ni}_{2}$ is the most isotropic of all phase. In addition to $\mathrm{Al}_{3} \mathrm{Ni}$ and $\mathrm{Al}_{3} \mathrm{Ni}_{2}$ are brittle materials, other intermetallics are tougher materials. Among which, AlNi has the best toughness, and $\mathrm{Al}_{3} \mathrm{Ni}_{2}$ has the best brittleness. The study of Debye temperature suggests that $\mathrm{Al}_{3} \mathrm{Ni}$ has the highest Debye temperature, AlNi has the lowest Debye temperature.
\end{abstract}

\section{Introduction}

Aluminum alloy is a kind of extensive nonferrous metal material, which is widely used in aerospace, automobile, machinery manufacturing industry. Aluminum-nickel (Al-Ni) alloy has high-strength, lower density and oxidation resistance and corrosion resistance in a variety of aluminum-based alloys [1]. However, it has ductility which limits its application [2]. W.Lin and Tresa M. Pollock et al. [3] have found that the Al-Ni alloys have poor ductility at room temperature. Chan et al. [4] have found that toughness and ductility of Al-Ni alloy can be improved by grain refinement and alloying. The anisotropy of crystal is an important parameter to measure the mechanical properties of the material, It can let us know the cause of the micro-cracks in the material.

The micro-structure and micro-cracks of the Al-Ni crystal should be widely attention. In this work, the structural, toughness, elastic anisotropy and Debye temperature will be investigated within the density functional theory (DFT) framework for Al-Ni crystal.

\section{Computational Details}

In this study, the Al-Ni phases are adopted from Ref. [5] The generalized gradient approximation (GGA) [6] with the Perdew-Wang (PW91) functional is adopted to describe the exchange and correlation interaction. The ultra-soft pseudo-potentials (USPP) methods are used to study the interactions between ions and valence electrons [7]. A plain wave cutoff energy is set to $490 \mathrm{eV}$. Brillouin zone intergations are set to a Monkhorst-Pack $k$-point mesh [8], the k-point mesh of each cell has been sampled by $2 \times 2 \times 3,4 \times 4 \times 4,10 \times 10 \times 10,2 \times 2 \times 4,4 \times 4 \times 4$ grids for $\mathrm{Al}_{3} \mathrm{Ni}_{2} \mathrm{Al}_{3} \mathrm{Ni} 2, \mathrm{AlNi}$, $\mathrm{Al}_{3} \mathrm{Ni}_{5}, \mathrm{AlNi}_{3}$, respectively.

The elastic anisotropy can be described by defining universal index $\left(A_{U}\right)[9]$.

$$
\begin{aligned}
& A_{U}=\left(5 G_{V} / G_{R}+B_{V} / B_{R}-6\right) \times 100 \\
& B_{V}=1 / 9\left(C_{11}+C_{22}+C_{33}\right)+2 / 9\left(C_{12}+C_{23}+C_{13}\right)
\end{aligned}
$$




$$
\begin{aligned}
& G_{V}=1 / 15\left(C_{11}+C_{22}+C_{33}\right)-1 / 15\left(C_{12}+C_{23}+C_{31}\right)+1 / 5\left(C_{44}+C_{55}+C_{66}\right) \\
& 1 / B_{R}=\left(S_{11}+S_{22}+S_{33}\right)+2\left(S_{12}+S_{23}+S_{13}\right)
\end{aligned}
$$

$$
15 / G_{R}=4\left(S_{11}+S_{22}+S_{33}\right)-4\left(S_{12}+S_{23}-S_{13}\right)+3\left(S_{44}+S_{55}+S_{66}\right)
$$

where $B_{V}, G_{V}, B_{R}$ and $G_{R}$ are the Voigt bulk modulus, Voigt shear modulus, Reuss bulk modulus, and Reuss shear modulus respectively.

The Debye temperature $\left(\Theta_{D}\right)$ can be obtained through this equation [10].

$$
\begin{aligned}
& \Theta_{D}=h / K_{B}\left[3 \mathrm{n} / 4 \pi\left(N_{A} \rho / M\right)\right]^{1 / 3} V_{m} \\
& V_{m}=\left[1 / 3\left(2 / V_{s}^{3}+1 / V_{I}^{3}\right)\right]^{-1 / 3} \\
& V_{I}=\sqrt{1 / \rho(B+4 G / 3)}, V_{s}=\sqrt{G / \rho}
\end{aligned}
$$

where $h$ and $K_{B}$ are constants of Planck and Boltzman respectively. $\mathrm{n}$ is the number of atoms in a compound. $N_{A}$ is the Avogadro's number. $M$ is the molar mass of the compounds. $V_{m}$ is the average sound velocity. $V_{1}$ and $V_{S}$ are the longitudinal sound velocity and transverse sound velocity respectively.

\section{Results and Discussion}

\section{Structures}

According to the phase diagram [1], five kinds of structures of Al-Ni intermetallics are adopted. Further, the crystal structures of the Al-Ni intermetallics are optimized. The crystal configurations of them are shown in Fig. 1. Table 1 lists the optimized lattice parameters and compared them with the previous values. It can be seen that the results agree well with the experimental values.

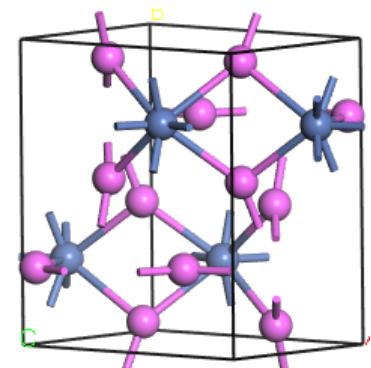

$\mathrm{Al}_{3} \mathrm{Ni}$

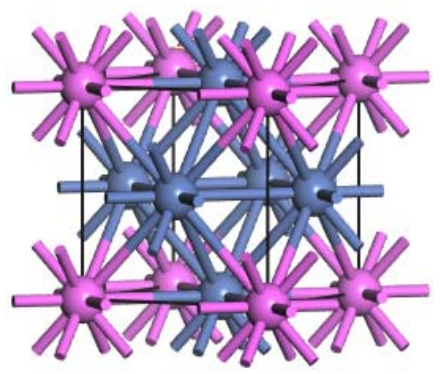

$\mathrm{AlNi}_{3}$

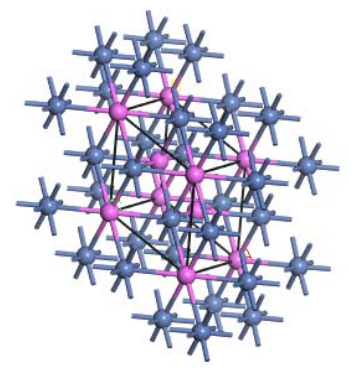

$\mathrm{Al}_{3} \mathrm{Ni}_{2}$
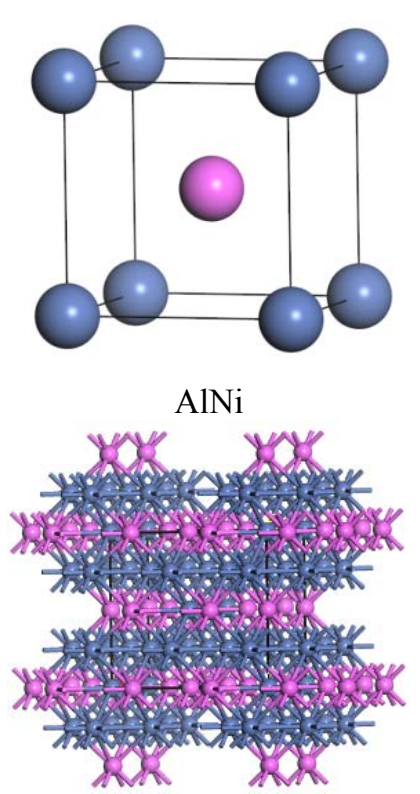

$\mathrm{Al}_{3} \mathrm{Ni}_{5}$

Fig. 1. The crystal configurations for the Al-Ni intermetallics. 
Table 1 The structural parameters for the Al-Ni phases.

\begin{tabular}{|c|c|c|c|c|c|}
\hline \multirow{2}{*}{$\begin{array}{c}\text { Phase } \\
\text { Al }\end{array}$} & \multirow{2}{*}{$\begin{array}{c}\text { Space group } \\
F m \overline{3} m\end{array}$} & \multicolumn{3}{|c|}{ Lattice constants $(\AA)$} & \multirow{2}{*}{$\begin{array}{l}\text { Reference } \\
\text { This study }\end{array}$} \\
\hline & & $a=4.018$ & & & \\
\hline & & $a=4.014$ & & & [11] \\
\hline \multirow[t]{2}{*}{$\mathrm{Al}_{3} \mathrm{Ni}$} & Pnma & $a=6.471$ & $b=7.478$ & $c=4.779$ & This study \\
\hline & & $a=6.598$ & $b=7.352$ & $c=4.802$ & {$[5]$} \\
\hline \multirow[t]{2}{*}{$\mathrm{Al}_{3} \mathrm{Ni}_{2}$} & $P \overline{3} m 1$ & $a=4.153$ & & $c=4.959$ & This study \\
\hline & & $a=4.219$ & & $c=5.161$ & {$[5]$} \\
\hline \multirow[t]{3}{*}{ AlNi } & $\operatorname{Pm} \overline{3} m$ & $a=2.873$ & & & This study \\
\hline & & $a=2.886$ & & & {$[12]$} \\
\hline & & $a=2.895$ & & & {$[13]$} \\
\hline \multirow[t]{2}{*}{$\mathrm{Al}_{3} \mathrm{Ni}_{5}$} & $\mathrm{Cmmm}$ & $a=7.520$ & $b=6.480$ & $c=3.780$ & This study \\
\hline & & $a=7.440$ & $b=6.680$ & $c=3.720$ & {$[5]$} \\
\hline \multirow[t]{2}{*}{$\mathrm{AlNi}_{3}$} & $P m \overline{3} m$ & $a=3.553$ & & & This study \\
\hline & & $a=3.566$ & & & {$[6]$} \\
\hline \multirow[t]{2}{*}{$\mathrm{Ni}$} & $F m \overline{3} m$ & $a=3.503$ & & & This study \\
\hline & & $a=3.514$ & & & {$[14]$} \\
\hline
\end{tabular}

\section{Elastic Anisotropy}

A zero value of $A_{U}$ indicates elastic isotropy, while the deviation of the 0 value indicates the anisotropic behavior of the material. $B_{V}, B_{R}, G_{V}, G_{R}$ and $A_{U}$ values are given in Table 2. Table 2 shows that all of the Al-Ni intermetallics are anisotropic. The $A_{U}$ value of AlNi is 940 , the $A_{U}$ value of $\mathrm{Al}_{3} \mathrm{Ni}_{2}$ is 1.01 , The more the $A_{U}$ value, the more the degree of elastic anisotropy. It can be understood as the AlNi phase is most likely to induce micro-cracks, While the $\mathrm{Al}_{3} \mathrm{Ni}_{2}$ phase is most hardest to induce micro-cracks. Secondly, the value of $\mathrm{Al}_{3} \mathrm{Ni}_{5}$ is greater than $\mathrm{AlNi}_{3}$, and the value of $\mathrm{AlNi}_{3}$ is greater than $\mathrm{Al}_{3} \mathrm{Ni}$, which shows the order of degree of anisotropy is $\mathrm{Al}_{3} \mathrm{Ni}_{5}>\mathrm{AlNi}_{3}>\mathrm{Al}_{3} \mathrm{Ni}_{\text {. }}$. 
Table 2 The bulk modulus,shear modulus for the Al-Ni intermetallics.

\begin{tabular}{|c|c|c|c|c|}
\hline Phase & $B_{V R H}(G P a)$ & $G_{V R H}(G P a)$ & $A_{U}$ & $B / G$ \\
\hline \multirow[t]{3}{*}{$\mathrm{Al}_{3} \mathrm{Ni}$} & $B=119.13$ & $G=74.77$ & -35.37 & 1.59 \\
\hline & $B_{V}=119.21$ & $G_{V}=72.01$ & & \\
\hline & $B_{R}=119.05$ & $G_{R}=77.52$ & & \\
\hline \multirow[t]{3}{*}{$\mathrm{Al}_{3} \mathrm{Ni}_{2}$} & $B=92.92$ & $G=74.04$ & 1.01 & 1.25 \\
\hline & $B_{V}=94.09$ & $G_{V}=73.92$ & & \\
\hline & $B_{R}=91.74$ & $G_{R}=74.15$ & & \\
\hline \multirow[t]{3}{*}{ AlNi } & $B=162.74$ & $G=45.01$ & 940 & 3.62 \\
\hline & $B_{V}=166.75$ & $G_{V}=66.77$ & & \\
\hline & $B_{R}=158.73$ & $G_{R}=23.24$ & & \\
\hline \multirow[t]{3}{*}{$\mathrm{Al}_{3} \mathrm{Ni}_{5}$} & $B=186.48$ & $G=64.35$ & 353.39 & 2.90 \\
\hline & $B_{V}=187.76$ & $G_{V}=81.10$ & & \\
\hline & $B_{R}=185.19$ & $G_{R}=47.59$ & & \\
\hline \multirow[t]{3}{*}{$\mathrm{AlNi}_{3}$} & $B=181.49$ & $G=97.29$ & 46.66 & 1.87 \\
\hline & $B_{V}=187.54$ & $G_{V}=101.01$ & & \\
\hline & $B_{R}=175.44$ & $G_{R}=93.57$ & & \\
\hline
\end{tabular}

\section{Toughness}

$B / G$ is widely used to characterize the toughness of the intermetallics. For brittle materials, $B / G$ is less than 1.75 (Diamond, $B / G=0.8$ ). For tougher materials, $B / G$ is greater than 1.75 (A1, $B / G=2.74$ ). In addition to $\mathrm{Al}_{3} \mathrm{Ni}$ and $\mathrm{Al}_{3} \mathrm{Ni}_{2}$ for brittle materials, the other intermetallics are tougher materials. The value of the AlNi phase is the largest in these phases, which shows that it has the best toughness. The value of $\mathrm{Al}_{3} \mathrm{Ni}_{2}$ is the smallest $(B / G=1.25)$, less than $\mathrm{Al}_{3} \mathrm{Ni}(B / G=1.59)$ and $\mathrm{AlNi}_{3}$ $(B / G=1.87)$ in the brittle material, which shows that the $\mathrm{Al}_{3} \mathrm{Ni}_{2}$ has the best brittleness, and the brittleness of $\mathrm{Al}_{3} \mathrm{Ni}$ is larger than that of $\mathrm{AlNi}$.

\section{Debye Temperature}

In a solid material, Debye temperature $\left(\Theta_{D}\right)$ is closely related to the elastic moduli and quantum effects [15]. A higher Debye temperature values indicate a higher thermal ductivity and more powerful chemical bonds. Moreover, A large Debye temperature crystal will be a hard crystal. The operation results are shown in Table 3. From the table we can illustrate $\mathrm{Al}_{3} \mathrm{Ni}$ has the highest Debye temperature, suggesting it has the highest thermal conductivity and the strongest chemical bond among these five intermetallics, it also shows that the hardness is the largest in the five kinds of intermetallics. AlNi has the lowest Debye temperature, the chemical bond is the weakest in five kinds of intermetallic compounds. The energy required to destroy its chemical bond is also lowest compared to the other four intermetallic compounds. The calculated $\mathrm{AlNi}_{3}$ of the Debye temperature is $531.88 \mathrm{~K}$, which is very close to the experimental result $(550 \mathrm{~K})$. The effects of experimental conditions and environmental factors are ignored, which may be the cause of the deviation between the calculated results and the experimental results [16]. 
Table 3 The calculated values including $V_{l}, V_{S}, V_{m}$ and $\Theta_{D}$.

\begin{tabular}{ccccc}
\hline Phase & $V_{l} / m \cdot s^{-1}$ & $V_{S} / m \cdot s^{-1}$ & $V_{m} / m \cdot s^{-1}$ & $\Theta_{D} / K$ \\
\hline $\mathrm{Al}_{3} \mathrm{Ni}$ & 7559.69 & 4418.97 & 4899.34 & 589.65 \\
$\mathrm{Al}_{3} \mathrm{Ni}{ }_{2}$ & 6553.58 & 4073.51 & 4490.10 & 544.80 \\
$\mathrm{AlNi}$ & 6081.43 & 2733.68 & 3083.17 & 402.97 \\
$\mathrm{Al}_{3} \mathrm{Ni}{ }_{5}$ & 6332.93 & 3078.73 & 3459.77 & 456.82 \\
$\mathrm{AlNi}_{3}$ & 6418.15 & 3588.53 & 3994.47 & 531.88 \\
& & & & $550^{[16]}$
\end{tabular}

\section{Conclusion}

In summary, we have performed computations on the structures, elastic anisotropy, toughness and Debye temperature of the Al-Ni crystal using all-electron DFT-PW91 calculations. The results reveal that the the degree of anisotropy of AlNi phase is the highest, and the degree of anisotropy of $\mathrm{Al}_{3} \mathrm{Ni}_{2}$ is lowest, this shows that $\mathrm{AlNi}$ is the most easily induced micro-cracks, and $\mathrm{Al}_{3} \mathrm{Ni}_{2}$ is the most difficult to induce micro-cracks. The $\mathrm{AlNi}, \mathrm{Al}_{3} \mathrm{Ni}_{5}$ and $\mathrm{AlNi}_{3}$ are ductile materials, the $\mathrm{Al}_{3} \mathrm{Ni}$ and $\mathrm{Al}_{3} \mathrm{Ni}_{2}$ are brittle materials, the toughness of $\mathrm{AlNi}$ is the best, the toughness of $\mathrm{Al}_{3} \mathrm{Ni}_{2}$ is the poorest. The $\mathrm{Al}_{3} \mathrm{Ni}$ has the highest Debye temperature, the AlNi exists the lowest Debye temperature, which shows that $\mathrm{Al}_{3} \mathrm{Ni}$ has the highest thermal conductivity and the strongest chemical bond, while the thermal conductivity of AlNi is the lowest, and the chemical bond is the weakest. Meanwhile, the calculation result of $\mathrm{AlNi}_{3}(531.88 \mathrm{~K})$ is roughly the same as the experimental value $(550 \mathrm{~K})$, which indicates that the results of this study are accurate.

\section{Acknowledgments}

It was supported by Grant No. 51374128 from the National Natural Science Foundation, People's Republic of China.

\section{References}

[1] K. Morsi, Review: reaction synthesis processing of Ni-Al intermetallic materials, Mater. Sci. Eng. A. 299 (2001) 1-15.

[2] R.D. Noebe, R.R. Bowman, M.V. Nathal, Physical and mechanical properties of the B2 compound NiAl, Int. Mater. Rev. 38 (1993) 193-232 .

[3] Paul O. Adebambo, Bamidele I. Adetunji, Joseph A. Olowofela, James A. Oguntuase, Gboyega A. Adebayo, Structural, Electronic, Magnetic and Optical Properties of Ni,Ti/Al-based Heusler Alloys: A First-Principles Approach, Z. Naturforsch. A. 71 (2016) 129-134.

[4] K.S. Chan, Theoretical analysis of grain size effects on tensile ductility, Scr. Metall. Mater. 24 (1990) 1725-1730.

[5] S. Jiang, S. Li, Valence Electron Structure Calculation and Interface Reaction Prediction of Phases in Ni-Al System, Rare Metal Mater. Eng. 40 (2011) 1355-1360.

[6] M.C. Payne, M.P. Teter, D.C. Allan, T.A. Arias, J.D. Joannopoulos, Iterative minimization techniques for ab initio total-energy calculations: molecular dynamics and conjugate gradients, Rev. Mod. Phys. 64 (1992) 1045-1097. 
[7] D. Vanderbilt, Soft self-consistent pseudopotentials in a generalized eigenvalue formalism, Phys. Rev. B. 41 (1990) 7892-7895.

[8] H.J. Monkhorst, J.D. Pack, Special points for Brillouin-zone integrations, Phys. Rev. B. 13 (1976) 5188-5192.

[9] Kawsar Ali, A. Arya, Partha Ghosh, G. K. Dey, A first principles study of cohesive, elastic and electronic properties of binary Fe-Zr intermetallics, Comp. Mater. Sci. 112 (2016) 52-66.

[10] T. Min, Y.M. Gao, Y.F. Li, Y. Yang, R.T. Li, X.J. Xie, First-principles calculations study on the electronic structures, hardness and debye temperatures of chromium carbides, Rare Metal Mater. Eng. 41 (2012) 271-275.

[11] Crystallographic Laboratory, Cambridge, England, UK, Private Communication.

[12] P. Villas, L. Calvert, Pearson's Handbook of Crystallographic Data for Intermetallic Phases, American Society for Metals, Metal Park, OH, 1991.

[13] J.E. Garcés, G. Bozzolo, Determination of structural alloy equilibrium properties from quantum approximate methods, Phys. Rev. B. 71 (2005) 134201.

[14] L. Mazza, A.G. Nasini, XXXII. The crystal structure of nickel, Blackwell Publishing Ltd, 1929, PP. 68.

[15] C. Kittel, Introduction to Solid State Physics, 8th Edition, John Wiley \& Sons Inc, Hoboken, NJ, 2005.

[16] Y. Zhang, Y. Xie, W. Li, R. Tang, K. Gao, Debye temperature and physical properties of Ni3Al, T. Nonferr. Metal Soc. 6 (1996) 114-118. 